\title{
CLARÍN Y PICÓN: DEL DESENCUENTRO A LA AMISTAD
}

\author{
ESTEBAN GUTIÉRREZ DÍAZ-BERNARDO
}

\begin{abstract}
No abundan en nuestro planeta crítico los estudios sobre las relaciones personales entre escritores. ¿Será por púro desdén hacia lo que no es propiamente crítica ni historia literaria? ¿Por la dificultad, a veces insalvable, de rehacer episodios vitales mal conocidos o lisa y llanamente desconocidos? Sea como fuere, lo cierto es que abordar cuestiones como esta, a priori extraliterarias, supone en ocasiones sacar de la penumbra rincones oscuros de la personalidad o de la trayectoria de un autor, de su proceso creativo, y hasta de la consideración o la interpretación de su obra o de sus obras.

Es lo que pretendo aquí al exponer el resultado de mis indagaciones sobre la relación entre Clarín y Picón, que hasta ahora no pasaba de brindar un par de referencias puntuales: las doce cartas de Alas que editó en su día Amorós $^{1}$, y el artículo de Picón sobre el primer tomo de La Regenta ${ }^{2}$. Sin embargo, hay bastante más, y bien jugoso que es, se enfoque desde donde se enfoque.

Asociar a Leopoldo Alas (1852-1901) y Jacinto Octavio Picón (18521923) no solo no tiene nada de insensato, sino que parece poco menos que obligado, datos en mano. En su vida: rigurosamente coetáneos, solo cuatro meses y medio - los que corren del 25 de abril al 8 de septiembre de 1852habían separado sus respectivos nacimientos, en Zamora y Madrid. En su obra: los dos, autores de una destacada producción periodística y crítica (mucho más abundante y relevante en Clarín), de un reducido corpus novelís-
\end{abstract}

\footnotetext{
${ }^{1}$ Fue Antonio RAmos-Gascón (en el estudio introductorio a su edición de Pipá, Madrid, Cátedra, 1976 , p. 42 , n. 33) quien puso sobre la pista de este breve epistolario Clarín-Picón, que después publicó Andrés AMORós: «Doce cartas inéditas de Clarín a Jacinto Octavio Picón», Los Cuadernos del Norte, II, Núm. 7, mayo-junio 1981, pp. 8-20.

${ }^{2}$ PICón, Jacinto Octavio, «La Regenta. Novela de Leopoldo Alas (Clarín)», El Correo, 15-III-1885. Han reproducido el texto el mismo AMORós, «Doce cartas inéditas...», pp. 17-20; Valis, Noël M., «Dos artículos olvidados sobre La Regenta de Clarín», Boletín del Instituto de Estudios Asturianos, XXXVII, Núm. 109-110, mayo-diciembre 1983, pp. 648-652, y TintorÉ, María José, «La Regenta» de Clarín y la crítica de su tiempo, Barcelona, Lumen, 1987, pp. 120-126.
}

Rlit, LXVII, 134 (2005), 441-462 
tico (dos novelas de Alas, ocho de Picón), y de un importante número de cuentos (alrededor del centenar del asturiano, unos 125 del madrileño) ${ }^{3}$. Y hasta en su recepción posterior, marcada por el olvido en ambos casos; un olvido que para Alas no solo ha quedado definitivamente conjurado, sino que ha hecho del autor en nuestros días un auténtico clásico contemporáneo ${ }^{4}, \mathrm{y}$ un olvido del que Picón, lento pero seguro, parece que empieza a zafarse 5 .

No quiere esto decir que el valor de sus respectivas obras sea comparable: muy ciego o muy apasionado estaría quien no acertara a percibir la superioridad incuestionable de Clarín sobre Picón; pero ello no ha de ser obstáculo para considerar como se merece la importante producción del madrileño, tanto en su faceta crítica como narrativa. Tampoco corren parejas sus respectivas conductas personales y públicas, y aquí Alas se halla muy lejos de la tolerancia, de la nobleza de carácter y hasta de la bondad de Picón, como veremos en lo que sigue.

${ }^{3}$ Para Alas, véase la edición de Carolyn Richmond en ClaRín, Cuentos completos (Madrid, Alfaguara, 2000, 2 vols.), y en Leopoldo ALAs, Clarín, Obras completas, III. Narrativa breve (Oviedo, Nobel, 2003). Para Picón, mi próxima edición crítica de los Cuentos completos.

${ }^{4}$ En los últimos años, y especialmente a raíz de la conmemoración del centenario de su muerte, en 2001, el interés por Clarín ha crecido de manera espectacular, con hitos tan relevantes como el de la magna edición de sus Obras completas, en doce volúmenes (Oviedo, Nobel, 2002-en curso de publicación). Pero recuérdese que el BAQUERO GoYANES que reivindicaba sus cuentos en 1949 («Clarín, creador del cuento español», Cuadernos de Literatura, V, 1949, pp. 145-169) actuaba prácticamente como francotirador, y que La Regenta solo llegó al gran público a través de la edición de bolsillo de Alianza Editorial en 1966.

${ }^{5}$ Véase la impagable labor de Noël M. VALIS en sus varios artículos bibliográficos: «Una primera bibliografía de y sobre Jacinto Octavio Picón», Cuadernos Bibliográficos, XL, 1980, pp. 171-209; «Adiciones a una bibliografía de y sobre Jacinto Octavio Picón», RLit, XLIII, Núm. 93, 1985, pp. 165-171; «Más datos biobibliográficos sobre Jacinto Octavio Picón», RLit, LIII, Núm. 105, 1991, pp. 213-244; «Suplemento bibliográfico de y sobre Jacinto Octavio Picón», RLit, LXI, Núm. 122, 1999, pp. 557-563. A ellos puede añadirse Esteban GUTIÉRREZ DÍAZ-BERNARDO, «Para la bibliografía de Jacinto Octavio Picón», en Homenaje a Luis Morales Oliver, Madrid, Fundación Universitaria Española, 1986, pp. 151-157. En los últimos años se apunta una firme recuperación de don Jacinto, con trabajos de James Mandrell, Ángeles Ezama, Óscar Barrero, Cristina Anaya, Peter Bly, Robert Fedorchek, Soledad Romera, Enrique Miralles, Emilio Miró, María-Paz Yáñez, Yolanda Latorre, Ivón Valdés y de los propios Valis y Gutiérrez. Para las referencias bibliográficas puestas al día (que aquí nos apartarían en exceso de nuestro camino), consúltese Esteban GUTIÉRREZ DíAZ-BERNARDO, «Tres notas bibliográficas sobre Jacinto Octavio Picón: la supuesta segunda edición de Juanita Tenorio (1912), la fecha de Drama de familia y las novelas no publicadas» (febrero 2005), <http://www.bibliotecamiralles.org/ Originales/Notas_Gu.doc>. 


\section{PICÓN, PRIMERA VÍCTIMA DE LA CRÍTICA POLICÍACA}

Al margen de algún escarceo al que no atenderemos, 1875 es el año en que se inician las carreras, de momento solo periodísticas, de estos dos jóvenes licenciados en Leyes, ambos de 22 años cuando se asoman a las tribunas respectivas de El Solfeo, en el caso del asturiano, y de El Globo, en el del madrileño. Y así, Leopoldo Alas, firmando con este nombre, publica en $E l$ Solfeo un artículo titulado «Los pentacrósticos», que va dividido en dos partes: «Prólogo»y «Primer caso» ${ }^{6}$. Y escribe en la primera de ellas:

Me propongo, con la intención más sana, dedicar de vez en cuando algunas cuartillas a la literatura en estado de canuto, en connivencia con la Guardia Civil que persigue allá en los montes a los malhechores. Acción patriótica y desinteresada, que tal vez mis contemporáneos no estimen en todo lo que vale; pero yo me atengo... a la posteridad, tribunal de alzada para todos los genios ocultos.

Y hago bien porque la plaga va tomando proporciones alarmantes, y no habrá varita de las siete virtudes que pueda concluir con ella si se la deja tomar alas (esto es, llegar al estado de mariposa) ${ }^{7}$.

El profesor Botrel, su editor moderno, puso de relieve la extraordinaria importancia del texto, lo que aquí no haremos más que subrayar, ya que cuenta el pasaje con la virtud de plantear el concepto muy directa y sintéticamente ${ }^{8}$.

Pues bien, a continuación, el «Primer caso» nos presenta al crítico vapuleando de forma inmisericorde a un autor que no nombra, pero que es precisamente nuestro también jovencísimo don Jacinto, en su escrito titulado La torre de la Vela ${ }^{9}$. La burla resulta en verdad hiriente, y ciertamente el texto consiste en una fantasía cuasirromántica que de seguro al lector actual le parecerá tan trasnochada como a Alas. Desde luego dan ganas de alinearse con el crítico policíaco cuando, ante el pasaje: «Allí los ríos y las fuentes, la llanura y el monte, la morada del pobre y el palacio del rico, están habitados, al par que por los vivos de hoy...», comenta: «iQué calor! ¡Es cosa de irse a vivir a una fuente!». Lo mismo, tras esta oración: «En Sierra Ne-

\footnotetext{
${ }^{6}$ ALAS, Leopoldo, «Los pentacrósticos», El Solfeo, Año I, Núm. 15, 13-VI-1875.

7 Tomo el texto de AlAS, Leopoldo, Preludios de "Clarín». Estudio preliminar, selección y notas por Jean-François Botrel. Oviedo, IDEA, 1972, p. 9. Reeditado ahora en Leopoldo ALAS, Clarín, Obras completas, V. Artículos (1875-1878). Ed. Jean-François Botrel e Yvan Lissorgues. Oviedo, Nobel, 2002, p. 97.

${ }^{8}$ Anota Botrel (ed. Preludios de «Clarín», p. 9, nota 1): «Primera, y casi definitiva, definición de la crítica policíaca, higiénica, menuda, gramatical, o como se llame, tal como la practicará "Clarín" y de la que dio otra definición, más famosa pero poco diferente, en Palique (Prólogo, pp. XVIII-XXVII)».

9 PICón, Jacinto Octavio, «La torre de la Vela», El Globo, Año I, Núm. 68, 7-VI-1875, pp. 269-270. Lo reproduzco en el Apéndice final. Consúltelo el lector si desea seguir el detalle de mi exposición.
} 
vada las nieves esparcidas fertilizan la vega y fructifican la llanura» - que no es literal, pero que no traiciona en absoluto al original-, cuando escribe: «Bajemos de la sierra, señor autor, y entremos en el Diccionario: fructificar es verbo neutro como toser, estornudar, disparatar y otros muchos» ${ }^{10}$. Lo que no tiene duda, por cierto. Se agrega alguna otra pulla, más o menos gratuita, haciendo exhibición del agudo ingenio que caracteriza a Alas.

Pero otros pasajes satirizados nos sorprenden por su inexactitud, esto es, por el hecho de que el crítico manipula el texto para dar rienda suelta a su invectiva despiadada y mordaz. Desde el comienzo:

Sin más proemio, vengamos a lo primero, que es como sigue:

Encarámase el poeta (poeta en prosa) en la Torre de la Vela, y dice:

«El suelo que pisó Colón al tomar posesión del Nuevo Mundo, la que guarda los huesos de Virgilio, la que...».

Sin embargo, el comentarista se salta la palabra tierra, con lo que la cosa varía bastante. Quizá el párrafo sea poco airoso, pero no tan nítidamente erróneo como quiere Alas:

El suelo que pisó Colón al tomar posesión del Nuevo Mundo, con la vista en el cielo y la rodilla en tierra, la que guarda los huesos de Virgilio, la que...

Más abajo vuelve a la carga:

Los tajos y las simas enseñan, como enhiestas fauces, el centro de la tierra.

Pero léase a Picón:

En sus entrañas hay tajos y simas que, como abiertas fauces, enseñan el centro de la tierra.

Y se verá que no hay tal error: las «abiertas fauces» invalidan la censura. Finalmente:

Todavía dice el empingorotado autor, después de recobrar el uso de los sentidos, que Granada es el damasco de Occidente.

Pero léase de nuevo a Picón:

[...] mientras yo descendía hacia Bib-el-Leujar pensando aún en aquellos tiempos en que Granada fue la Damasco de Occidente.

De todo ello extraemos que podría sostenerse la calificación de «exageraciones fantástico-gramaticales», pero casi nada de lo demás.

Picón respondió indirectamente, con este suelto sin firma, en El Globo de tres días más tarde, que transcribo íntegro:

10 Alas, Leopoldo, Preludios de "Clarín», p. 10. De aquí mismo proceden las citas de «Los pentacrósticos. Primer caso» que van a continuación. 
El autor del artículo que publicamos en nuestro número del 7 del corriente, titulado La Torre de la Vela, ha leído la crítica que de su humilde trabajo hace en El Solfeo D. Leopoldo Alas, y nos dirige una carta en la que, respetando el derecho que ejerce tan noblemente el crítico, nos ruega que, en su nombre, le pidamos para lo sucesivo no incurra en la insignificante falta, sin duda involuntaria, de trastornar el orden de las palabras, cortar el sentido de las oraciones y atribuir al criticado frases que no aparecen impresas.

El Sr. Picón piensa seguir el consejo que le da el Sr. Alas, por lo visto, en connivencia con la Guardia civil, para entrar en el Diccionario, pero a su vez tiene la natural exigencia de que el Sr. Alas no se aparte del camino de la verdad cuando critique ${ }^{11}$.

La respuesta nos retrata de cuerpo entero a Picón: templado, no levanta la voz; modesto, acepta la crítica; pero no deja de poner al descubierto la falta de fundamento de las cuchufletas de Alas.

Este cargará de nuevo, y en un artículo en forma de carta al director, fechada en Oviedo el 22 de junio, escribe: «Dispénseme usted si voy a entretenerle por algunos momentos con dimes y diretes en que, muy a pesar mío, me veo metido por un señor Picón que ha tomado a mal ciertos inocentes desahogos de mi pluma novel y un poco maliciosa» ${ }^{12}$; protesta por el apelativo «mísero crítico (el señor Picón me lo llama)», lo que es rigurosamente falso; le designa, chanceándose, «ilustre poeta», y entre zumba y zumba, le afea dos errores de su artículo posterior «Arte y libertad», del mismo número en el que aparecía el suelto recién transcrito ${ }^{13}$. Picón no respondió y Alas no volvió a ocuparse de él por mucho tiempo.

\section{DEL SILENCIO A LA GRATITUD}

No obstante, cuando Picón edita su primera novela, Lázaro, en 1882, envía a Clarín un ejemplar, lo que deducimos de un «Palique» de junio de

${ }^{11}$ El Globo, Año I, Núm. 77, 16-VI-1875, p. 308.

12 ALAS, Leopoldo, «Cartas provincianas. Los pentacrósticos (continuación)», El Solfeo, Año I, Núm. 17, 27-VI-1875. Reproducida en Obras completas, $V$, cit., pp. 103-106.

${ }_{13}$ PICón, Jacinto Octavio, «Arte y libertad», El Globo, Año I, Núm. 77, 16-VI-1875, pp. 305-306. Clarín condena ahora la expresión «la personalidad, el más poderoso destello, el primer reflejo de la libertad individual» (que Alas traslada no literalmente, pero que no retuerce en su sentido), y el mal uso del término martirologio (y aquí al asturiano le asiste toda la razón). Había escrito don Jacinto: «fácilmente podríamos hacer biografías muy parecidas a martirologios sufridos en fuerza de injusticias, atropellos e iniquidades» (ambos pasajes, en p. 306). Y Clarín se relame: «Ahora un acertijo. ¿A que no saben los lectores qué es lo que suele sufrir el que se sacrifica por una causa? ¿El martirio? Pues no, señores... ¡El martirologio! Esto parece increíble, pero también lleva la marca del señor Picón, y no hay que darle vueltas. El que quiera cerciorarse de todo lo anterior, ya que el señor Picón me ha dejado tan poco crédito, le remito al artículo que con el rótulo de "Arte y Libertad" ha publicado recientemente el infatigable autor de La Torre de la Vela» («Cartas provincianas. Los pentacrósticos (continuación)». En Obras completas, V, p. 105). 
ese año, en el que su autor da cuenta de los libros que ha recibido por esos días, entre los cuales está la novela de Picón, sobre la que anuncia que escribirá tras haberla leído; cosa que no hará, por cierto ${ }^{14}$.

El silencio de Alas parece abonar el escaso aprecio que sentía por la novela de Picón, y por Picón mismo, lo que se corrobora sin sombra de duda cuando pocas semanas después escribe a José Yxart aconsejándole colaboradores para Arte y Letras: «Respecto de Arte declaro que yo no entiendo, y debe Ud. escoger mucho en esta materia, porque por desgracia en España no hay escritores que sepan hablar con originalidad de tal asunto. Hay aquí varios jóvenes (los Picón, Mourelo [?], Peña y Goñi, etc.) que unos de música, otros de pintura, escriben copiando o disparatando lindamente: huya Ud. de ellos» ${ }^{15}$. No hay duda del prejuicio de Alas para con don Jacinto: confiesa no entender del tema, pero sí sabe que Picón disparata; o tal vez es de los que copian, lo que resulta radicalmente falso. Una vez más aparece aquí el habitual Clarín caprichoso y atrabiliario.

Lo cierto es que no estima poco ni mucho a Picón, ni como crítico, ni como novelista. Al silencio tras Lázaro seguirán estas palabras escritas a don Benito Pérez Galdós dos años después: «Creo que empieza demasiada gente a escribir novelas, y al pensar, de repente, que yo también voy a prevaricar [con La Regenta] me dan escalofríos. Hablando en secreto, creo firmemente que los únicos novelistas verdaderos son Vd. y Pereda, y de la parte contraria Alarcón y algo Valera, cuando Dios quería». Y más adelante: «Armando [Palacio Valdés] tiene muchas cualidades de novelista, pero le faltan otras, y entre ellas la salud necesaria para estudiar mucho, penetrar la vida, las ideas, dar valor interior a sus cuadros: sin esto se hacen cosas bonitas, pero no basta. Esto mirando las cosas desde muy arriba; ahora, comparando a Armando con Picón, Navarrete, etc., me parece un águila; no sé si me cegará la pasión» ${ }^{16}$.

Por entonces, don Jacinto acababa de publicar (o estaba a punto de hacerlo) La hijastra del amor, que vería la luz a finales de mayo o principios

${ }^{14}$ «He recibido varios libros en estos días, y de todos diré a ustedes algo, pero tomándome el tiempo necesario para leerlos. I He recibido Lázaro, cuasi [sic] novela, por Octavio Picón. II Dos opúsculos del señor Vidart [...]» (Clarín, «Palique», El Progreso, 11-VI-1882. Reproducido en Leopoldo ALAS, Clarín, Obras completas, VI. Artículos (1879-1882). Ed. Jean-François Botrel e Yvan Lissorgues. Oviedo, Nobel, 2003, p. 1050, por donde cito). El signo I, que vuelvo a emplear más adelante, quiere indicar un punto y aparte del original. El título completo de la obra de Picón era Lázaro. Casi novela.

${ }^{15}$ La carta, no fechada, debe de ser de julio de ese año 1882. La publicó Sergio BESER, «Siete cartas de Leopoldo Alas a José Yxart», Archivum, X, 1960, pp. 385-397. La cita, con interrogante incluido, es de pp. 389-390.

${ }^{16}$ Carta de Clarín a Galdós sin fecha, pero, por la ordenación de los papeles de don Benito, de entre el 8 de abril y el 24 de julio de 1884. Tomo el texto de Soledad ORTEGA, Cartas a Galdós, Madrid, Revista de Occidente, 1964, pp. 220 y 221. 
de junio de 1884. Y es también por entonces cuando se inicia, o reinicia, el contacto epistolar entre nuestros dos autores ${ }^{17}$.

De la primera de las doce cartas conservadas de Clarín a Picón (11-XII1884), se infiere claramente que es este quien toma de nuevo la iniciativa, que lo hace en circunstancias especialmente adversas para Alas, a propósito del fallecimiento de su padre, y que la carta emociona verdaderamente al asturiano:

Mi querido amigo y compañero: el espontáneo, cariñoso y sincero pésame de Ud. me ha servido de mucho consuelo y se lo agradezco en el alma.

Aun las ocasiones más tristes de la vida sirven para estudiar a los hombres, y estos días de prueba me están haciendo aprender muchas cosas.

Gracias, muchas gracias, amigo Picón.

[...] Nunca olvidará su buena acción su antiguo y sincero amigo que M.G.B.S.M ${ }^{18}$.

Y algo más: de la misiva se desprende que en este período anterior se había producido un acercamiento entre ambos (¿quizá a raíz del envío de Lázaro?), que parece algo lejano en el tiempo:

Yo recuerdo que tiene Ud. unos hijos hermosos y una madre a quien quiere muchísimo; Dios se la conserve a todos y viva Ud. para eso, para quererla mucho.

Yo tengo iguales lazos y además lo que Ud. perdió tan pronto, una compañera $^{19}$.

\section{Más motivos para la gRatitud: Picón ANTE La REgENTA}

En fecha desconocida, pero que indudablemente es pocos días o semanas posterior a la recién citada, Clarín le anuncia el envío del primer tomo de La Regenta y le pide su opinión:

Mucho quisiera que Ud. se tomase el trabajo de leer el tomo, y si después de leído juzgaba que merecía decir algo de él, que lo dijese, o bien a mí, en particular; o, lo que yo preferiría, al público.

\footnotetext{
17 Entretanto, Clarín cita a Picón en un «Palique», de octubre de ese año, en el que ataca a Cañete por haberse apropiado de una idea de don Jacinto en su biografía de Ayala (PICóN, Jacinto Octavio, «Don Adelardo López de Ayala», en Autores dramáticos contemporáneos y joyas del teatro español del siglo XIX, vol. II, Madrid, Fortanet, 1882, pp. 377-379), según la cual el dramaturgo quizá debía a García Gutiérrez la presentación de El hombre de estado (Madrid Cómico, Año IV, Núm. 88, 26-X-1884). Véase ahora este texto en Leopoldo AlaS, Clarín, Obras completas, VII. Artículos (1882-1890). Ed. JeanFrançois Botrel e Yvan Lissorgues. Oviedo, Nobel, 2004, pp. 463-467.

${ }_{18}$ AMORÓs, «Doce cartas inéditas...», p. 11.

19 AMORÓS, «Doce cartas inéditas...», p. 11. En las citas que siguen, doy directamente, entre paréntesis, la fecha de la carta y/o la página de este artículo.
} 
[...] Tengo motivos especiales para desear conocer la opinión de Ud. Primero, el buen concepto que me merece su juicio, $2 .^{\circ}$ el saber lo que opina quien en tal materia profesa teorías muy parecidas a las mías. De las controversias ya supongo yo lo que puedo esperar.

Y añade: «Tengo seguridad de que Ud. escribirá algo, si cree que $L a$ Regenta lo merece, sin acordarse de descuidos míos antiguos y de frialdades recientes» (p. 12).

Así fue. De la posterior carta de Alas deducimos que Picón publicó un suelto en El Correo, sin firma, que no puede ser otro que este, del 26 de enero de 1885; una de las primeras reseñas, por cierto, de la novela:

La Regenta. Entre la gente de letras se sabía que una casa editorial de Barcelona tenía en su poder para publicarla una novela de Clarín, y la obra era esperada, por unos, con curiosidad, por otros, con verdadera impaciencia. La novela, que se titula La Regenta, se vende ya en las librerías y ha de ser objeto de grandes discusiones entre los literatos. El asunto del libro, su desarrollo, las costumbres que en sus páginas se reflejan, la tendencia que acusa y su estilo, han de proporcionar a La Regenta un éxito real y legítimo, pero que no sorprenderá seguramente a los que conocen a fondo las facultades de Clarín. Leopoldo Alas, al lanzarse al escabroso campo de la novela, demuestra el mismo talento e iguales condiciones de observador y de buen prosista a las que le han conquistado su envidiable reputación de crítico. Cuantos aquí siguen con interés el movimiento literario, saborearán con delicia La Regenta, y aun los que no se hallan conformes con su escuela ni con sus ideas, se verán obligados a rendir un tributo de admiración a la inteligencia y al ingenio de su autor. Ofrecemos a nuestros lectores ocuparnos detenidamente de este libro ${ }^{20}$.

Clarín le agradecerá no solo los elogios, sino «su noble y cariñosa conducta»; se mostrará halagado por la opinión favorable de su madre, doña Octavia Bouchet, y también por las de Ramos Carrión y Campoamor, que Picón debió de comunicarle en carta anterior:

No puede Ud. figurarse cuánto le agradezco, y cuánto me habla en favor de Ud., su noble y cariñosa conducta para conmigo. Había leído ya el suelto que Ud. me mandó, y aunque aquellos elogios eran visiblemente hiperbólicos yo no los agradecía menos por eso, sino más. Mucho me halaga que sea como Ud. dice la opinión que de mi libro tiene su señora madre (c.p.b.), pues aunque no tengo el honor de conocerla más que de vista, por lo de «de tal palo tal astilla» tomado en buen sentido saco en consideración el valor de su opinión. También me halaga mucho lo que Ud. dice de Ramos Carrión, que no tiene motivos para ser apasionado en mi favor, y lo de Campoamor, por más que este vaya Ud. a saber lo que piensa en realidad.

En su carta, a la vez, Picón debió de hablarle de Juan Vulgar, a punto de aparecer por esos días. A lo que Alas le responderá: «Con mucho gusto

${ }^{20}$ «Al menudeo», El Correo, 26-I-1885. Lo reproducen AMORós, «Doce cartas inéditas...», p. 9, y TinTORÉ, «La Regenta» de Clarín y la crítica de su tiempo, pp. 119-120. 
leeré su nueva novela y ya buscaré dónde decir algo de ella, porque ahora no tengo sitio fijo» (4-II-1885, p. 12).

Picón cumplirá lo prometido, ante la impaciencia y la insistencia de Clarín $^{21}$, y en el número de El Correo del 15 de marzo publicará un extenso artículo, excelentemente escrito, bajo el título «La Regenta. Novela de Leopoldo Alas (Clarín)», en el que se ocupa del ambiente, del asunto y en especial de los personajes; todo lo cual mueve a Picón a alabar el «talento extraordinario» de su autor, el estudio y observación que presenta, su alta originalidad y, quizá por sobre todo, su arquitectura impecable:

La novela surge del contacto de unos personajes con otros sin visible artificio, pero artísticamente planeada, tejida lenta y minuciosamente, a semejanza de esos chales de la India en que lo cuidadoso de la labor, hecha a menudos trozos, atrae primero las miradas y luego, cuando la tela se despliega, muestra un solo dibujo al cual todas las líneas secundarias se enlazan y todos los detalles obedecen como dispuestos armónicamente para dar realce a lo principal ${ }^{22}$.

Conviene añadir que al elogio explícito habría que sumar el implícito, en el sentido de que Picón, y esto lo tuvo siempre muy a gala, jamás hizo crítica de novelas, sosteniendo que no debía el crítico ocuparse de obras del mismo género de las que él componía ${ }^{23}$. Por ello, la mera redacción del artículo es indicio de la excepcional relevancia que don Jacinto concede a la novela. Y lo cierto es que Alas quedará encantado, y escribe radiante a Picón:

${ }^{21}$ Es lo que se desprende de una carta de Palacio Valdés a Alas, de mediados de febrero, en la que aquel escribe: «He visto a Picón ya dos o más veces y me ha prometido solemnemente ocuparse del libro; no sé si lo ha cumplido porque no leo El Correo; presumo que no porque me lo dirían» (TOLIVAR AlAS, Ana Cristina, «Once cartas inéditas de Leopoldo Alas Clarín», Clarín y su tiempo: exposición conmemorativa del centenario de la muerte de Leopoldo Alas (1901-2001), Oviedo, Cajastur, 2001, pp. 229-242. Cito por la edición electrónica de la Biblioteca Virtual Miguel de Cervantes: <http:// www.cervantesvirtual.com/bib_autor/Clarin/estudiosinvest.shtml>. El pasaje, en pp. 240241. La carta, según su editora, es del 1[?][sic] de febrero).

22 PICÓN, Jacinto Octavio, «La Regenta. Novela de Leopoldo Alas (Clarín)», El Correo, 15-III-1885. Reproducen el texto AMORÓs, «Doce cartas inéditas...», pp. 17-20; VAlis, Noël M., «Dos artículos olvidados sobre La Regenta de Clarín», Boletín del Instituto de Estudios Asturianos, XXXVII, Núm. 109-110, mayo-diciembre 1983, pp. 625652 (el texto de Picón, en pp. 648-652); y TiNTORÉ, «La Regenta» de Clarín y la crítica de su tiempo, pp. 120-126.

${ }^{23}$ Hasta entonces, ni siquiera con Galdós, de quien se consideraba discípulo, había hecho excepción. Esto escribía en su reseña, que no crítica, de La de Bringas, lo que nos sirve como muestra de una posición que mantuvo toda su vida: «Ante todo, este no es un artículo de crítica, pues no debe el escritor juzgar producciones del mismo género a que se dedica, que el apasionamiento de escuela y el espíritu de compañerismo cortan alas a la realidad. Solo me propongo llamar la atención del público hacia la última obra del escritor insigne que primero en los Episodios Nacionales y luego en las Novelas Contemporáneas ha trazado una admirable serie de oftografías [sic] sociales, donde juntos y en el mismo desorden con que la realidad los muestra aparecen retratados los vicios, las virtudes y las costumbres de la España moderna» (PICón, Jacinto Octavio, "La de Bringas», El Imparcial, 14-VII-1884). 


\begin{abstract}
¿Necesito decirle lo muy agradecido que le estoy? Recibí los dos ejemplares. Su artículo de Ud. está hecho con amor, se ve allí la parcialidad del amigo, pero disimulada con el talento del crítico que al exponer un asunto sabe mejorarlo. El análisis es fino, penetrante, y los elogios, que son excesivos, hiperbólicos, están condimentados con cierto aire de imparcialidad que produce ilusión. Pero imparcialidad no la hay. Es artículo de amigo, diga Ud. lo que quiera. Quéjese quien deba, a mí me toca agradecérselo de todo corazón (19-III-1885, pp. 12-13).
\end{abstract}

La emoción de Alas es indudable. Véase, si no, lo que por entonces escribe a Galdós: «El pobre Picón se ha portado conmigo como un caballero. Ha demostrado verdadera grandeza de alma. Yo no sé si podré pagarle en la moneda que a él más le gustaría, pero estoy seguro de que siempre le estaré agradecido» ${ }^{24}$.

\title{
4. Clarín (NO) PAGA SUS «DEUDAS DE GRATITUD»
}

En esa misma carta del 19 de marzo, añadía Alas que esperaba con impaciencia Juan Vulgar y prometía a Picón un artículo sobre esta novela. Será dos meses después cuando dé cuenta epistolar de su lectura de la obra, con un elogio que es puro compromiso:

He leído Juan Vulgar y estoy conforme con la opinión de mi mujer que lo había leído antes; es un libro muy natural, que interesa de veras, hecho con suma discreción, conocimiento del clima [?] y de la vida actual y con un estilo que me parece el más recomendable para obras de esta índole. En este punto, tal vez uno de los principales, creo que Juan Vulgar lleva ventaja a sus novelas anteriores. Para mí el estilo de la novela de hoy es ese. El lenguaje es muy correcto, y mire Ud. que yo en este punto hilo delgado; pues sí señor, encuentro que resiste el análisis victoriosamente.

Por lo mismo que el libro no es de pretensiones encanta con su modestia, y si le falta, porque así lo quiso el autor, miramiento exterior, lo tiene en el alma; pues hace pensar y sentir. Creo que está Ud. en el mejor camino, y que para ahondar en el dispositivo [?] social y expresarse lisa y correcta y sinceramente es para lo que Ud. sirve principalmente, sin perjuicio de describir con fuerza, precisión y abundancia cuando llegue el caso. Mi enhorabuena de todo corazón ${ }^{25}$.

En la misma misiva, hace alusión a La República de las Letras, sin citar nombre, y asocia también a Picón al proyecto galdosiano: «Galdós insiste en que se publique un órgano nuestro, Novum organorum, que diría Bacon; yo estoy dispuesto a gastar tinta y hasta un poco (poco) de dinero si es menester» (p. 14). Lo que corrobora en carta posterior: «Galdós me habla largo y

24 S. ORTEGA, Cartas a Galdós, p. 228. Aunque la carta va sin datar, no hay duda de que es inmediatamente posterior a la aparición de La Regenta, pues en ella Clarín agradece a don Benito su opinión sobre la novela.

25 Sigo citando, aquí y a continuación, por AMORós, «Doce cartas inéditas...», p. 13. La carta es del 21-V-1885. Los interrogantes son del transcriptor. 
tendido de nuestro órgano y un día ya hablé a Ud. de la cuestión» (12-VII1885, p. 14). Pero poco después escribía a don Benito sobre los posibles colaboradores: «Y Picón, gran alma, gran entusiasmo... es un sectario y... en fin, habría que tener cuidado con él $»^{26}$. Parece que a Alas le había caducado la gratitud.

Volviendo a la carta del 21 de mayo, lo más interesante surge en torno al ofrecido artículo sobre Juan Vulgar: «si a Ud. le parece hablaré de Juan Vulgar speciatim en El Globo, pero si he de serle franco, temo lo que Ud., que crean que son aplausos mutuos» $(21-\mathrm{V}-1885$, p. 13).

Y lo hubieran sido, no cabe duda, si Clarín hubiera hecho realidad ese artículo que nunca existió. $\mathrm{O}$ en efecto lo fueron, si tenemos en cuenta lo que escribió, en una modestísima nota al pie, en su crítica de El idilio de un enfermo, de Palacio Valdés. Tras citar a Ortega Munilla y al propio Palacio como «los dos únicos [jóvenes] que hasta ahora han dado pruebas de ser novelistas verdaderos», añade aquí, en la nota aludida, agregada para la edición en libro: «Después de escrito este artículo, ha publicado J.O. Picón, reputado crítico, dos novelas muy bien recibidas por el público, La hijastra del amor y Juan Vulgar, revelando dotes muy dignas de aprecio. Vaya esto como rectificación de lo que se lee en el texto. Y no digo más, porque no crea la malicia que pago aquí deudas de gratitud» ${ }^{27}$.

Las cartas siguientes, de julio, septiembre y octubre del 85 y de enero del 86, insisten, y mucho, en el prometido artículo de Picón sobre $L a R e$ genta completa, una vez dado al público, en el verano de aquel año, el segundo tomo de la novela: «En esta pesadez conocerá Ud. que doy gran valor a su promesa y que quiero que de un modo u otro me la cumpla, siempre y cuando no le moleste» (23-I-1886, p. 16).

En torno a estas fechas recogemos dos nuevas alusiones de Clarín a Picón, muy leves, pero que no dejan de ser significativas de un cierto cambio

${ }^{26}$ S. ORTEGA, Cartas a Galdós, p. 233. A pesar de que la editora da la fecha del 3 de julio de 1883, parece indudable, como vio Amorós, que en el año debe de haber errata, y tratarse de 1885. Tanto el orden de las cartas como el contenido de esta así lo abonan. En cuanto a La República de las Letras, es el título de un periódico que pretendía fundar Galdós y «en el que solo podrían colaborar la Pardo Bazán, Picón, Pereda, Galdós, Clarín, Armando Palacio y Menéndez Pelayo, si quiere». Trae el dato Juan Antonio CABEZAS («Clarín». El provinciano universal, Madrid, Espasa-Calpe, 1962, p. 130), quien no ofrece más precisiones. Tal vez se trate de un intento de reemprender la publicación del semanario que con esa misma cabecera había aparecido ya en 1881, lo que no se haría realidad hasta veinte años después, justamente bajo el amparo de Galdós, y en el que Picón no colaboraría. Véase el muy útil repertorio de María Pilar Celma Valero, Literatura y periodismo en las revistas del fin de siglo. Estudio e índices (1888-1907), MadridGijón, Júcar, 1991, especialmente pp. 102-105 y 808-814.

${ }^{27}$ Clarín (Leopoldo Alas), ...Sermón perdido, Madrid, Fernando Fe, 1885, p. 237. Véase ahora en Leopoldo AlAS, Clarín, Obras completas, IV. Crítica (Primera parte). Edición de Laureano Bonet, con la colaboración de Joan Estruch y Francisco Navarro. Oviedo, Nobel, 2003, p. 598. 
en la consideración literaria que del madrileño tiene el asturiano, inducida quizá por la noble conducta de Picón, o por sus elogios a La Regenta, o por ambas cosas. Se trata, en primer lugar, de su artículo «España en Francia», reseña de Le naturalisme en Espagne (1885), de Albert Savine, en el que simplemente escribe, a propósito de lo que trae el crítico francés sobre los novelistas jóvenes que siguen las huellas de Galdós: «me parece justo lo que dice de Oller, Armando Palacio, Picón y otros» ${ }^{28}$. Precisemos que lo que Savine decía, en síntesis y siempre sobre La hijastra del amor, era que Picón se había revelado en ella como novelista valioso («romancier de valeur»), que se trataba de una obra vigorosa, aunque demasiado espesa («trop touffue»), en la que destacaba el atrevimiento de algunas páginas («avec des pages hardies»), la observación que la nutría y la emoción que desprendía («beaucoup d'observation et d'émotion»). Acababa considerando a su autor apegado aún en exceso a Zola («ces cinq cent trente pages, tout en affirmant la puissance de M. Picón, ne le montrent pas encore assez dégagé du sillage des maîtres français, et tout particulièrement de M. Émile Zola»), y la novela, como una promesa de futuro, especialmente en lo tocante a su heroína («le livre de M. Picón est une promesse: sa Clara nous intéresse») ${ }^{29}$.

La segunda de las alusiones pertenece a un «Palique» de enero de 1886, en el que da cuenta de lo que preparan por esas fechas Palacio Valdés, Pereda, Galdós y Picón, y se lamenta de que no escriban novelas Alarcón y Valera. Lo que dice de don Jacinto no tiene mayor relieve en sí mismo ( cón está cosiendo una Sotana. Si lo que se propone es dar a luz un cura más, sólo le suplico una cosa... ique no sea mestizo! No, no más mestizos... ni en broma» $)^{30}$, pero resulta significativo de ese cambio de opinión, al mencionarlo entre los grandes novelistas.

También del lado humano parece que la conducta de Picón ha desarmado definitivamente las reticencias de Alas. No hay por qué pensar que este no sea sincero en la despedida de su carta de enero del 86: «Tengo grandes deseos de darme una vuelta por ahí, y gran parte de mi ansiedad es por apretar una mano tan experta como leal y charlar con Ud. y otros pocos de tantas y tantas cosas» ${ }^{31}$.

28 «España en Francia. Le naturalisme en Espagne, por Alberto Savine.-París, E. Giraud et Compagnie, Éditeurs», Mezclilla, Madrid, Fernando Fe, 1889. Cito por la edición de Antonio Vilanova, Barcelona, Lumen, 1987, pp. 267-273. La cita, en p. 273. El artículo de Clarín ha de datarse sin duda en el mismo 1885.

${ }^{29}$ SAVINE, Albert, Le naturalisme en Espagne. Simples notes, Paris, Nouvelle Librairie Parisienne, E. Giraud \& Cie., 1885, p 50.

${ }^{30}$ Clarín, «Palique», Madrid Cómico, Año VI, Núm. 154, 30-I-1886. Lo reproducen Botrel y Lissorgues en su edición de las Obras completas, VII, pp. 562-565. Alude a la novela que acabará titulándose El enemigo (Madrid, Est. Tip. de El Correo, a cargo de F. Fernández, 1887).

${ }^{31}$ Carta del 23 de enero de 1886. De nuevo en AmORós, «Doce cartas inéditas...», p. 16. 
En todo caso, la alta opinión que don Jacinto tiene de Clarín no ha variado. Y así, en su esporádica sección de «Libros» de $E l$ Correo, hablará en mayo de 1888 de Mis plagios, o más bien de la segunda parte del volumen, Un discurso de Núñez de Arce, no solo para elogiar cálidamente la defensa que hace Alas del naturalismo, compartiendo sus puntos de vista, alabando su erudición al argumentar sobre la novela como género y su fortuna al tratar sobre la prosa y el verso, sino para calificar de admirable su exposición. Y concluir con estas palabras tan favorables como clarividentes: «Clarín es al mismo tiempo un crítico notabilísimo y un escritor satírico de primer orden: confieso que me gusta más cuanto es mayor en cada uno de sus trabajos la separación que establece entre ambas personalidades» ${ }^{32}$.

\section{AMigos}

Nuevo salto en el tiempo. Nada nos ha llegado de la relación entre Clarín y Picón en los años inmediatos. Hasta que en 1894 un curioso episodio los une otra vez: el libro Literatura extranjera, de Enrique Gómez Carrillo, que su autor dedica a Leopoldo Alas, el cual, precisamente a causa de este hecho, había juzgado que no debía ser él quien escribiese el prólogo. Así lo explica don Jacinto, que será finalmente el encargado de redactarlo: «Al dedicar V., amigo Gómez Carrillo, Literatura extranjera a Leopoldo Alas, creyó este que no debía escribir el prólogo, acordando ambos que yo lo hiciera; a lo cual me presté gustoso por ver mi nombre honrado en compañía de los suyos».

Y continúa con un elogio de Clarín que evidencia una vez más la admiración que Picón le profesa, y con una declaración de la modestia que le es natural. Importa reproducir todo ello:

Quien sale perdiendo es V., porque el literato que se ampara de otro debe procurar que tenga gran prestigio, y el de Leopoldo es indiscutible. Con su autoridad, y a propósito de V. y su libro, hubiera escrito unas cuantas cuartillas llenas de ideas hondas, propias del caso, y cuajadas de esos rasgos de ingenio merced a los cuales expresa cuanto quiere en la medida que se lo propone. Su ilustración, su facultad de exponer claramente lo mucho que sabe y su poderoso talento para defender lo que patrocina o atacar lo que condena, le han creado la reputación que tiene. Porque no solo es excelente novelista y pintor de costumbres -díganlo La Regenta y iAdiós, Cordera! - sino que además de las cualidades que para ello hacen falta, posee el arte maravilloso de descubrir y analizar las condiciones e índole de los escritores, determinando el parentesco intelectual que hay entre ellos. Es de los afortunados que saben buscar en el pensamiento ajeno, estudiando, con sujeción a ideas propias, lo que otros discurren; de suerte que casi siempre persuade, y cuando no lo consigue deleita con lo que dice y por el modo de decirlo. En él la sensibilidad del artista no merma la serenidad del crítico: percibe la belleza conservando calma para meter en ella el escalpelo.

\footnotetext{
${ }^{32}$ PICÓN, Jacinto Octavio, «Libros. Folletos literarios. Mis plagios», El Correo, 6-V-
} 1888 . 
Yo - pronombre tan antipático como necesario- cuando escribo críticas, me acuerdo demasiado de que soy novelista, complaciéndome particularmente más en ver cómo son las gentes y las cosas que en averiguar su porqué; mis instintos, algo materialistas, se detienen al llegar a ciertas profundidades; y, sintiéndome lleno de contradicciones y dudas, peco de ecléctico y tolerante, si es que puede haber pecado en la tolerancia.

Conque, ya ve V. lo que ha perdido en el cambio. Buscaba V. un verdadero crítico, y da con un mero impresionista. No espere V., pues, un estudio digno de sus brillantes facultades y de Literatura extranjera: tiene V. que contentarse con una simple causerie. Haga V. cuenta que paseamos por el jardín del Luxemburgo, o que estamos almorzando junto al Sena en algún alegre cabaret... Entre copa y bocado charlemos amigablemente ${ }^{33}$.

La amistad parece ya finalmente encauzada, como evidencia un artículo de El Imparcial del 31 de agosto de 1896, en que incidentalmente Picón se refiere a «mi amigo Leopoldo Alas» ${ }^{34}$. Antes, a raíz del fracaso de Teresa (20-III-1895), una carta de Clarín a Luis París nos muestra a don Jacinto no solo como uno de los que apoyaron al asturiano, no solo formando parte de su círculo de amistades, sino entre aquellos cuyo juicio es atendido por este: «Yo vuelvo al teatro, por supuesto. A los ocho años ya hacía comedias; las hice hasta los 22; las dejé y ahora vuelven ellas solas con gran fuerza, juicio, plan, propósito firme y hondo y precisado. Me animan Echegaray, Galdós, Balart, Picón, etc., etc. ¿Por qué no?» ${ }^{35}$.

Por otra parte, la corta vida de Alas aún alcanzará para dar testimonio de dos de los principales logros de Picón en estos años: la publicación del Velázquez y su ingreso en la Real Academia Española. La aparición de la monografía sobre el pintor sevillano es tema único de esta breve carta:

Oviedo, 20 junio, 1899.

Mi querido amigo: hoy, por fin, llegó su libro, que le agradezco infinito, y en el cual pienso aprender muchas cosas. $\mathrm{O}$ yo veo mal o es la única obra importante publicada con motivo del centenario de Velázquez.

Haré toda la propaganda que pueda de su libro.

Ya sabe que le quiere muy de veras y por muchos conceptos su affmo. amigo invariable

Leopoldo Alas $^{36}$.

${ }^{33}$ PICÓN, Jacinto Octavio, «Prólogo» a GómEZ CARRILlO, Enrique, Literatura extranjera. Estudios cosmopolitas, París, Garnier Hermanos, 1895, pp. III-XV. Las dos citas, en p. III y pp. III-V, respectivamente. El texto de Picón va fechado en octubre de 1894.

34 Se trata del artículo «El último libro de Menéndez Pelayo», que apareció en Los Lunes de El Imparcial de esa fecha.

${ }^{35}$ Clavería, Carlos, «Una nueva carta de Clarín sobre Teresa», Hispanic Review, XVIII, Núm. 1, january 1950, pp. 163-168 (p. 165). Reproduce la carta, en el contexto del estreno de Teresa, Guillermo GuASTAVINO, «Algo más sobre Clarín y Teresa», Bulletin Hispanique, LXXIII, Núm. 1-2, janvier-juin 1971, pp. 133-159 (p. 136).

36 AMORós, «Doce cartas inéditas...», p. 16. Clarín alude a PICón, Jacinto Octavio, Vida y obras de don Diego Velázquez, Madrid, Fernando Fe, 1899. 
Volverá a aparecer el Velázquez en su epístola siguiente, del 25 de febrero de 1900, en la que se muestra complacido por la carta de Picón, amable y cariñoso (¡qué lejos queda el Clarín autosuficiente y policíaco de los años jóvenes!): «Yo, que le leo siempre, pienso mucho en Ud. I Es claro que recibí y leí y gusté su Velázquez y de él di noticias en los periódicos»; y a la vez enfermo y abatido: «Yo trabajo sin fe, sin esperanza... y sin caridad para con mi pobre estómago y mi pobre ingenio»; le pide que escriba en la prensa sobre la reprise de La Regenta, que aún habrá de esperar un año largo para ver la luz, y le felicita por su acceso a la Real Academia Española: «Mi enhorabuena por su justísima elección para la Academia. De esto también recuerdo haber hablado en papeles» (pp. 16-17).

Precisamente este, el de la Academia, será el tema único de la última carta, del 17 de abril de 1900, en la que Clarín aplaude la idea de Picón de consagrar todo su discurso a la figura de Castelar, pone algún reparo a que sea Valera quien le conteste, por la diferencia de temperamento entre don Juan y don Emilio («Acaso hubiera hecho una cosa más de corazón Echegaray», p. 17), y se extiende sobre Castelar, a quien conoció bien y de quien escribió con frecuencia.

A esta solemnidad académica dedicará Clarín el último artículo que trata sobre Picón. El último, pocos meses antes de su muerte, y uno de los escasísimos en que lo hace. No quisiera equivocarme, pero creo que desde esas dos sátiras iniciales de «Los pentacrósticos», Alas no había vuelto a consagrar un texto por entero a Picón ${ }^{37}$. En todo caso, plantea una muy curiosa correlación con esos «pentacrósticos» de 1875 en que se despachaba a gusto contra el joven don Jacinto: hallamos al primer y al último Clarín en esta singular disimetría, que refleja bien el cambio operado en Alas y, menos, en Picón. Ciertamente Picón es ahora mejor escritor, pero Clarín es mejor persona, más humano, más generoso ${ }^{38}$. Y le aplaude sin rodeos:

Aunque sea ya acontecimiento lejano la solemnidad académica en que Jacinto Picón leyó su discurso de ingreso en la Española, el discurso mismo no se ha hecho viejo, ni es tarde para dedicarle, siquiera sea en pocas palabras, el elogio que merece. Está bien escrito, en el tono propio del caso, pero sin amaneramientos hieráticos de ese fetichismo que algunos quieren agregar a la tradición literaria ${ }^{39}$.

Alaba la oportunidad de consagrar el discurso por entero al homenajeado, y más cuando la figura y la obra de Castelar van cayendo en el olvido

\footnotetext{
${ }^{37}$ Disculpará el lector la cautela, que muy pronto podremos abandonar, cuando se complete la magna edición de las Obras completas de Alas que voy citando (ya bastante avanzada en el momento de redactar estas líneas), y podamos tener a nuestro alcance toda la obra crítica del asturiano.

38 «Polémiste quinteux et injuste» ('polemista caprichoso e injusto') le llamó Albert SAVINE, Le naturalisme en Espagne, p. 27.

${ }^{39}$ Clarín, «Revista literaria», El Imparcial, 16-VII-1900.
} 
—escribe Clarín—, del que Picón («noble, leal, sincero [...]; valiente, no osado») le rescata; para concluir:

Bienaventurado Picón, tan noble y sincero como el genial vallisoletano, y en esta ocasión más acertado, a mi ver, al proclamar en el mundo entero la gloria, ya segura, del gran profeta de las libertades españolas y del ideal espiritualista ${ }^{40}$.

Vemos, pues, cómo a lo largo de estos veinticinco años evolucionan positivamente unas relaciones que parecían condenadas de entrada al fracaso más estrepitoso. La admiración de Picón hacia Clarín, pero sobre todo su generosidad y nobleza, harán que el asturiano acabe viendo en don Jacinto al hombre por encima del escritor: un amigo bien vale un elogio.

\section{APÉNDICE}

\section{LA' TORRE DE LA VELA ${ }^{41}$}

Hay en el planeta que habitamos sitios que, vistos desde regiones superiores, deben ser puntos luminosos, parajes donde el espíritu y el humano esfuerzo deben haber dejado, como huellas, un rastro esplendoroso: lugares iluminados por el heroísmo, alumbrados por la virtud, envueltos en una aureola misteriosa que los ojos de la materia no distinguen, pero que deslumbra a los ojos del alma. El suelo que pisó Colón al tomar posesión del Nuevo Mundo, con la vista en el cielo y la rodilla en tierra, la que guarda los huesos de Virgilio, la que recibió en sus grietas y empapó en sus entrañas la sangre del Cristo, deben lanzar en el silencio de la noche misteriosos fulgores, y dejar oír, confundidos con los quejidos de las auras, ruidos de voces sobrenaturales que entonen un cántico en loor de los bienhechores del linaje humano, y un himno de adoración a lo infinito. La gruta del Pausilipo, las Termópilas, el Calvario, deben brillar entre las sombras y despedir las ráfagas de luz, los resplandores que emanan de las grandes virtudes y los grandes hechos. Así, ennoblecidos por las acciones de los hombres, inmortalizados por los héroes, por los genios, por las razas, hay tierras que son sagradas, hay valles que son cunas y llanuras que son sepulcros de un pueblo o de una civilización; árboles que son columnas vivas que inmortalizan un gran suceso, peñascos que son como los altares de una gran idea.

Y uno de esos parajes que hablan a nuestro espíritu, despertando en la imaginación sombras y recuerdos, memorias y leyendas, es Granada.

${ }^{40}$ ClARÍn, «Revista literaria», cit.

${ }^{41}$ El Globo, Año I, Núm. 68, 7-VI-1875, pp. 269-270. Modernizo ortografía y acentuación conforme a los usos actuales, pero respeto empleos propios del autor (media noche) y extranjerismos (rawí, almée), así como unifico mayúsculas y minúsculas en términos que en el original (torre de la Vela, barrio del Deleite) aparecen con formas dobles. Mantengo tal cual la puntuación, salvo en el caso de los signos de interrogación del pasaje ¿Qué se hizo de aquella Toledo [...] que tenía Granada?, que en el texto de El Globo aparece integrando una única pregunta. 
Allí los ríos y las fuentes, la llanura y el monte, la morada del pobre y el palacio del rico, están habitados, al par que por los vivos de hoy, por las apariciones y los fantasmas, por las historias y las consejas de las edades pasadas; y en los vientos que bajan de las sierras vecinas vienen los poéticos conjuros a cuya evocación despierta la ciudad dormida y resucita la Granada muerta. Contemplarla desde una gran altura es subir a una gran elevación en la historia y ver desde allí toda una época, dos civilizaciones y dos pueblos. Por eso yo quería ver a Granada desde la torre de la Vela, y subí a ella bajo los rayos de un sol abrasador, en la mitad del día, y al llegar a la plataforma tendí la vista en torno, y la mirada mía se hundió en un mar de luz, en un océano de resplandores, en un inmenso piélago de deslumbrante claridad que no me permitía distinguir objeto alguno entre aquella luz que, al refractarse en la nieve de los montes y el agua de los ríos, en la blancura de las casas y el verde claro de la extensión inmensa de la vega, lo envolvía y lo iluminaba todo con la irradiación de lo divino, bajo un cielo azul, inconmensurable, purísimo, y un sol que ardía como un diamante de fuego engastado en el centro de una gran turquesa.

Volví a la noche, y como había visto a Granada a la luz del sol, la vi a los rayos de la luna. Ya la había visto con su manto de oro, y quise verla con su túnica de plata. El silencio de la noche, el misterio de las sombras, la evocación de los recuerdos, la memoria de lo leído, sumergen allí al espíritu en éxtasis profundo y la Granada cristiana desaparece para que aparezca la Granada árabe, la Granada de Alhamar el Magnífico. Tendí la vista entonces, y sentí dilatarse la pupila como si quisiera abarcar con una mirada lo infinito.

Detrás, Sierra Nevada con la blanca diadema de nácar de sus eternas nieves que va lentamente derritiendo el sol para que, en fecundas venas esparcidas, fertilicen la vega y fructifiquen la llanura. En sus entrañas hay tajos y simas que, como abiertas fauces, enseñan el centro de la tierra; lagos como espejos donde se reflejan bosques vírgenes, y hay canteras de las que podrían sacarse cien Alhambras; fósiles que son como esqueletos de otras vidas, ruinas que son tesoros de las generaciones venideras, plantas de los eternos fríos en la cima, vegetación de la feliz Arabia en la vertiente, abetos y tejos de la Scitia en la cumbre, palmas y laureles de la sagrada Palestina en la llanura, y al Mediodía las crestas mondadas de la Alpujarra. A la derecha el Sacro Monte, con cuevas como catacumbas, reliquias de santos y recuerdos de hombres ilustres; la fuente del Avellano, que Chateaubriand comparaba a la de Vaucluse; el cerro de San Miguel, que hoy sustenta una ermita donde antes estaba la torre del Aceituno, y el Darro, siempre cerniendo sus arenas de oro y bañando el Albaicín, hoy convertido en cerro de escombros, vivienda de mendigos y donde antes, en torno de una gran mezquita, tenían los moros principales sus casas de recreo, y hoy nuestros poetas raudal inagotable de tradiciones y leyendas.

En los grandes patios de sus palacios, mirándose en sus clarísimas albercas, al son de guzlas berberiscas, relataba el rawí sus cuentos de hadas y sus romances bélicos, mientras la luz de las lámparas de Bassora 
iluminaba el cristal de los estanques estrechados por sus cinturas de arrayanes.

A lo lejos está Santa Fe, campamento de piedra, prueba de la constancia castellana y del tesón aragonés, a la izquierda el Genil, la ciudad nueva, a la espalda el Generalife, y detrás las minas de Dar-la-Roca, el palacio de la novia, y allá, casi en el límite del horizonte, en la intersección de las dos sierras, el Suspiro del Moro, donde un rey débil dejó escapar por el labio contraído el jay! supremo de dolor al abandonar entre los hombres de hierro la ciudad más hermosa del mundo, la favorita del Profeta, la bendita de Alá, la despertada por el sol, la adormecida por la luna.

¡Oh Granada! Trescientos años no han podido hacerte cristiana: aún a la caída de la tarde se oye la voz del muecín en tus alminares, aún se deslizan por tus encrucijadas los gomeles, los almoradíes, los reduanes, los abencerrajes y zegríes, atizando con el fuego de sus ardientes venas tus eternas discordias: todavía en los ajimeces de la Alhambra y hacia la media noche, en los patios del barrio del Deleite, en todo tu recinto, en todos tus jardines, parecen respirar las moras en los frescos alhamíes, mientras la almée danza sobre el tapiz de Persia, los pies desnudos, ceñida por un velo, cuajadas las trenzas de flores de granado, desnuda y sin collares la garganta, con ajorcas de oro en las muñecas, con costoso azul miniadas las uñas, la canción del poeta en los labios, y el dolor de la esclavitud en el alma.

$\mathrm{Ni}$ la sangre de la conquista ni la intolerancia de la paz te han podido hacer cristiana. Destruirán los siglos tus alcázares y tus jardines; tus arcos, tus torres y minaretes, morderán el polvo, y sobre sus ruinas nacerán montes de ortigas, hará el reptil de tus escombros su vivienda, pero nada podrá trocarte en una ciudad cristiana, nadie te infiltrará el agua del bautismo.

En los tiempos bárbaros, en pleno feudalismo, una raza que no era española cayó sobre tu tierra, te conquistó, te hizo agarena, te esclavizó con el hierro y tú la esclavizaste con las dulzuras de tu clima, con el ambiente de tus jardines, con el sonoro arrullo de tus aguas. España entera peleó ocho siglos para reconquistarte, y al recobrar tu libertad se desvaneció tu grandeza: perdió una ciudad cristiana, y al penetrar en ella la halló mora. Aún están en pie muchas de tus obras; y junto a ellas los cristianos han querido edificar las suyas: ni aun el genio del Renacimiento ha podido luchar contigo. A pesar del palacio de Carlos $\mathrm{V}$ y de la catedral, a pesar de la chancillería y la Cartuja, eres árabe. Tu Alhambra todo lo oscurece, tu Generalife todo lo eclipsa. Ahí están a la espalda de esta torre, cuya campana regula con su voz metálica los riegos de la vega.

¡Alhambra la roja! Todavía vives, y cuando todo duerme tú despiertas. Vives con la vida de la poesía y los recuerdos, con el prestigio de la muerte, con el encanto del misterio, con el alma de la tradición y la leyenda.

Cae sobre ti la noche, y cuando, como ahora, las estrellas te envían los tímidos besos de su azulada luz, brotan de entre el ramaje y surgen de la linfa de las fuentes las sombras de los que te habitaron, de los que te labraron murallas como blondas, jardines como nidos: y vienen a ti los 
que jugaban cañas en Bib-Rambla, los que corrían toros en el Zenete, los que comerciaban en el Zacatín, los que vivían en Hajariz, el barrio del Deleite, los que guardaban la Cádima Alcazaba y las Torres Bermejas, los que después de la batalla, cubiertos de polvo y sangre, enrojecido el alquicel y sudoroso el potro, subían por la cuesta de los Gomeles a descansar en tus estancias de las fatigas del día, para libar en tu seno los placeres de la noche.

Desde esta torre los ojos de la materia alcanzan mucho. Una ciudad entera, muchos montes, verdes unos, calvas de toda vegetación las frentes de otros, una llanura inmensa, ríos como cintas de metales preciosos, torres envueltas entre brumas como guardianes silenciosos; pero los ojos del espíritu ven mucho más. Ven una raza entera agitarse y bullir en tierras remotas; pasar como un turbión el África, envuelta entre las tempestades del desierto, cuajar el mar de naves que con sus blancas velas asemejan bandadas de palomas, saltar en tierra los ejércitos, conquistar rápidamente, y como por ensalmo, una región que Roma empleó siglos en someter y Cartago no dominó sino por la astucia, apoderarse de ella como el más fuerte, conservarla como el más sabio, y perderla, por fin, como el más débil. Y durante una larga época cuando no eran ya los conquistadores árabes los que vivían, sino los nacidos en la tierra conquistada, hicieron de ella un paraíso para la vida del cuerpo, y un templo para la vida del alma. Aquel mundo muerto por Isabel I, y enterrado por Felipe III, no era un pueblo bárbaro, ni era civilización extranjera: el universo entero la designa hoy con el nombre de la España árabe. Eran entrambos pueblos de religión distinta, pero eran españoles. ¿Qué quedaba ya en 1492 de los salvajes acaudillados por Tarik y por Muza?

Las ciencias y las artes de aquellos que combatimos por extranjeros, solo porque adoraban otro Dios, ¡cuántas veces hicieron de España el objeto de sus estudios y de sus inspiraciones! Ahmad Ben-Mohamad, de Jaén, fue en su siglo el propagador de la poesía épica entre nosotros; Said Ben-Ahamad, de Almería, fue autor de una historia de España; Mahomad Ben-Kalaf, de Elvira, escribió una obra sobre Dios y Mahoma; Abderramán Abú-Giafar, discípulo del gran Averroes, hizo un tratado de derecho español; Abdelmagid, de Ronda, escribió una biblioteca arábigo-hispánica; Vaía Ben-Alsafarí escribió las hazañas de varios reyes de España; todos los grandes ingenios de aquel tiempo trabajaban por fundar, entre españoles y árabes, la misma unión que otros destruían por la fuerza. La España árabe fue uno de los focos más vivos que la civilización ha tenido en el mundo: la medicina, el álgebra, la poesía, la historia, hicieron progresos maravillosos, y cuando Granada, último baluarte del islamismo, último centro de todas aquellas artes, postrer asilo de todas aquellas ciencias, cayó en poder de los cristianos, un fraile mandó quemar los ejemplares del Corán, y los soldados de la fe hicieron ceniza aquellos prodigios del ingenio humano, del saber arábigo, que era el saber de nuestra España.

El fanatismo religioso hoy, como el fanatismo guerrero en los siglos que fueron, pueden considerar como una gran victoria la reconquista de Granada; pero la ciencia sufrió allí pérdidas inmensas. Esa lucha homé- 
rica sostenida por los sectarios de la cruz contra los de la media luna, aquel combate de ochocientos años, fue por la unidad religiosa, no fue por la idea de la patria: fue una guerra civil, como lo fue más tarde la insurrección de las Alpujarras. Y luego, cuando España una y católica agotó las fuerzas que había adquirido en aquella lucha, conquistando un mundo y descubriendo otro, ¿qué nos quedó? ¿Qué se hizo de aquella Toledo, que llegó a tener 200.000 habitantes?; ¿de Sevilla, la arteria donde con más fuerza palpitaba el arte?; ¿de Córdoba, donde más brillaba el saber?; ¿de Salamanca, que los extranjeros llaman todavía la madre de las virtudes y de las ciencias?; ¿qué fue de los 5.000 tornos de seda que tenía Granada? Astillas para las hogueras de la Inquisición.

Así se alejaba alguna vez mi mente de la ciudad que veía a mis pies en la histórica torre de la Vela: y, como guerrero de las antiguas algaradas, unas veces mi espíritu vagaba por la tierra agarena, otras por la cristiana, pero sin poder concebir que la ciudad de los nazaritas hubiera muerto.

La luna se había ocultado entre el fantástico celaje de esas nubes a que los vapores de la sierra dan vida tan fácilmente; la ciudad había quedado en sombra y sólo el vago y mortecino resplandor de las estrellas vertía su claridad confusa sobre árboles, casas, templos, torres y palacios.

Entonces fue cuando todo el tropel de ideas que bullían en mi cerebro tomó cuerpo, y creí ver humanizarse los fantasmas que solo en mi imaginación vivían.

Hubo un momento que vi a Granada volver al esplendor de su grandeza. Pareció hundirse todo lo moderno, y resucitar todo lo antiguo. Por las calles, por las plazas, por las alamedas, en la Vega, se agitó la muchedumbre árabe; oí el trotar de los caballos en Bib-Rambla, y los gritos de vendedores que pregonaban alhajú de Ronda, tortas de Alhama y roscones de Jaén. Hacia el barrio del Deleite, los ecos de las gaitas de Fez, y el ruido que producían al bailar sobre tableros de pino los enanos de Marruecos con zapatos de madera; en los altos ajarafes, entoldados por enredaderas y jazmines, resonaban los cantos del desierto acompañados de adufes y sonajas; cantos que aún conservan nuestros pueblos como herencia de los hijos del Profeta; quejidos, lamentos amarguísimos unos, promesas y juramentos dulces otros, pero manifestaciones todos de nuestras costumbres y nuestro carácter. ¿Quién no ha oído uno de esos cantos en que el cautivo se queja, las espaldas laceradas por el látigo y sumido en la lobreguez de la mazmorra? ¿Quién en Andalucía no ha escuchado, en el silencio de la noche, una de esas canciones que, precedidas de un ¡ay! desgarrador, llegan al alma como llegaría al rostro una lluvia de lágrimas que azotara el viento?

Centelleaban las estrellas y murmuraban las auras: yo absorto veía como la resurrección de un pueblo lo que no era sino un momento de alucinación. Y, como para ayudarme a volver de mi letargo, en aquel momento la luna quebraba con sus rayos las gasas de la nube que la envolvía y plateaba de nuevo la frente de la sierra y la corriente de los ríos; en todas las torres se veía la cruz, y al sonoro tañido de la campana de la Vela vino a mezclarse el «alerta» de los centinelas del recinto, 
mientras yo descendía hacia Bib-el-Leujar pensando aún en aquellos tiempos en que Granada fue la Damasco de Occidente. Y no es extraño que un rey suspirara al perderla de vista llena de poderío y de grandeza, pues hoy también suspira el que la deja cubierta de ruinas y poblada por los fantasmas que acuden a los conjuros y las evocaciones del poeta.

$\mathrm{Ni}$ es tampoco extraño que los descendientes de los que la habitaron se leguen hoy en África de padres a hijos la llave de la casa que en Granada vivieron, cuando era para los creyentes de Mahoma búcaro de nardos, pebete de aromas, la cuna de la luz, el lecho del amor, la ciudad sagrada.

Jacinto Octavio Picón

3 de junio de 1875, Madrid. 


\title{
RESUMEN
}

Clarín y Picón: del desencuentro a la amistad, por Esteban Gutiérrez DíazBernardo.

El conocimiento del trato entre escritores desvela a veces momentos significativos de su vida y facetas relevantes de su personalidad. Así ocurre en el caso de la relación, hasta hoy apenas estudiada, entre Leopoldo Alas y Jacinto Octavio Picón, dos autores rigurosamente coetáneos, con una trayectoria y una obra paralelas en más de un aspecto. Corresponderá a Picón el dudoso honor de ser el primer blanco de la sátira mordaz del joven Alas, que se ensañará con quien, sin embargo, le replicará modesta y mesuradamente. La reacción de Picón ante sendos hechos trascendentales de la vida personal y la carrera literaria de Clarín, la muerte de su padre y la publicación de La Regenta, favorecerá un acercamiento que acabará por vencer las muchas reticencias de Alas, hasta alcanzar una sincera amistad en los años finales de la vida del asturiano.

Palabras clave: Clarín, Picón, La torre de la Vela, Los pentacrósticos, crítica policíaca, epistolario, La Regenta, Lázaro, Juan Vulgar, novelas.

\begin{abstract}
The study of the interactions between authors sheds some light on several aspects of their lives. That is the case of the barely studied relationship between Leopoldo Alas and Jacinto Octavio Picón, two writers with parallel existences in personal and literary terms. Picón was the first target of Alas' biting satire, to which Picón responded with modesty and caution. However, following these tense first steps, their relationship changed due to two key events in Clarín's life and Picón's reaction to both of them; the death of Clarín's father and the publication of La Regenta fostered a reconciliation that eventually transformed the initial disputes into a warm friendship.
\end{abstract}

Keywords: Clarín, Picón, La torre de la Vela, Los pentacrósticos, policial critique, epistolary, La Regenta, Lázaro, Juan Vulgar, novels. 